\title{
Web-based Employee Assistance Programs: a New Exploration of Employee Service* $^{*}$
}

\author{
Zhun Gong \\ Institute of Psychology, Chinese Academy of Sciences, Beijing, China \\ gongz@psych.ac.cn \\ Shasha Yin \\ Academy of Psychology and Behavior, Tianjin Normal University, Tianjin, China \\ may1986530@126.com.cn \\ Yong Wang** \\ Institute of Psychology, Chinese Academy of Sciences, Beijing, China \\ wangy@psych.ac.cn
}

\begin{abstract}
Employee Assistance Programs (EAPs) are free, voluntary benefit which plan to help employees and their families cope with everyday problems. EAPS provide a wide range of services including short-term counseling, crisis intervention, occupational mental health and referrals. Since their rise approximate fifty years ago, EAPs have undergone fundamental changes. They have extended range and deepened the intensity of the services which they offer to employees and currently many EAPs offer a wider range of counseling. As the number of EAPs has grown, their organizational structure has become increasingly more complex and need a fire-new pattern to adapt it. The appearance of web has just met the demand of EAPs' development, and it forms a new mode: web-based Employee Assistance Programs. This article describes EAPs, their history, development, and reviews the cases of web-based Employee Assistance Programs. It sets the stage for considering EAPs as we move into the web-based century.
\end{abstract}

Keywords: EAPs(Employee Assistance Programs); web-based EAPs; employees; employers; the Internet

\section{Introduction}

Employee Assistance Programs (EAPs) are an employer-funded resource offered to employees and, often, to their families [1]. It is a human resource management tool that uses psychology, organizational behavior, management and other management theories and technologies, simultaneously integrates individuals, families, organizations and society resources to improve the organizational performance. They identify "troubled employees", motivating them to resolve their troubles, and providing access to counseling or treatment for those employees who need these services.

With the rapid economic and social development, individuals are facing with increasing pressure of work and life, so that EAPs have formed comprehensive services, gradually developing a more broad service area. They offers a wide range of services including personnel counseling [2][3][4], crisis intervention $[5][6][7][8]$ and occupational mental health [3][9]. Recently, as a means of cost containment, more EAPs are providing limited, short-term treatment to employees before referrals. Sometimes resolving these problems is a stressful process and it can bring on feelings of anxiety. EAPs provide confidential counseling and referral services including: workplace issues, family problems, stress, financial difficulties, legal problems, alcoholism, drug abuse, marital problems, depression, grief and loss, health and fitness, personal growth and well-being.

EAPs research has been extended from America to Europe, Japan, Taiwan, Hong Kong and many other countries and regions, in practice to be proved to be a powerful theory and tool to solve employee's physical and mental health problems and improve organizational performance. EAPs in recent years

\footnotetext{
* This study is founded by the Knowledge Innovation Project of the Chinese Academy of Sciences (No.KSCX2-YW-R-130) and the Special Fund for Beijing Key Discipline Construction (applied psychology, 2008 2012). ** Correspondence should be E-mail to Yong Wang: wangy@psych.ac.cn
}

978-1-4244-6359-6/10/\$26.00 @2010 IEEE 
begun to enter our country, and in some enterprises, institutions, troops, it has achieved some effect. However, because of the differences in cultural and concept, many organizations and individuals can not really understand it. The purpose of this review is to provide a brief overview of the history of EAPs and web-based Employee Assistance Program, hoping to provide more suggestions for future research.

\section{The origin and development of EAPs}

EAPs have a relatively brief period of history. EAPs originated in the early 20th century in the United States. Some companies began to notice that alcoholism, drug addiction and other drug abuse would affect the performance of employees and businesses, so they employed experts to solve these problems and put forward occupational alcoholism programs. From 1940s of the 20th Century, occupational alcoholism programs have been gradually popular in a number of enterprises in America, at the same time some enterprises extend the contents of occupational alcoholism programs to the mental and emotional aspects of staff. In 1960s, because of dramatic changes in American society, drug abuse, domestic violence, work stress, divorce, illness, legal disputes and other issues also affected their emotions and work, thus increasing the contents of occupational alcoholism programs has become an inevitable trend[10][11][12].

More and more enterprises began to execute the EAPs, to expand the scope of problem-solving of personal problems and raise the capacity of sloving problems. In 1985, the National Survey of Worksite Health Promotion Activities estimated that 24\% of private, nonagricultural US worksites with more than $50 \%$ employees offered an EAP [13]. In 1988, the Survey of Employer Anti-Drug Programs estimated that $6.5 \%$ of all private, nonagricultural worksites had an EAP [14]. In a subsequent study of these worksites in 1990, the estimated percentage of worksites with an EAP increased to $11.8 \%$ [15]. More recently, in 1991 Blum et al reported that $45 \%$ of full-time employees worked in firms with an EAP in their National Employment Study [16]. During this period, the companies mainly used some systematic intervention ways to understand, diagnose the behaviors of problem employees, and probe into the causes. And actively provide family, legal, medical, financial aid can help employees solve the problems. In short, the 1990 BLS follow-up study suggested a rapid increase in the provision of EAPs between 1988 and 1990. With respect to the form character, depending on the needs and resources of the employer, EAPs administratively were beginning to be related to a medical, human resources, or other departments of a company, acting either as an internal administrative unit or as an extemal contractor [17].

What can determine the prevalence of EAPs? Previous research indicated that worksite size was related to it. For example, the 1988 BLS study estimated that $71 \%$ of the largest worksites (i.e. those with more than 1000 employees) had an EAP while only $5 \%$ of the smallest worksites had not (i.e., those with fewer than 50 employees) [14]. This phenomenon was also found in the 1985 DHHS survey, the 1990 BLS follow-up study, and the National Employment Study. EAPs prevalence also affected by industry. The 1988 BLS survey found that the communication and public utilities industry had the highest EAPs prevalence rates of $76 \%$ compared with prevalence rates of $11 \%$ for the construction industry, $17 \%$ for retail trade, and $18 \%$ for wholesale trade [17]. Most providers have to consider the cost and effect of adopting an EAP. There is an urgent need and requirement to develop new mode of EAPs.

\section{The rise of web-based EAPs}

Over the last several decades, with the development of science and technology, the Internet has become a new communication medium that can make connection everytime and everywhere. It is integrated into all fields of our daily lives. The Internet represents the vehicle, which brings individuals, companies, and providers together. It's the place where people do information collection, seek life management resources and referrals. The web will help us contact people in convenient and interesting ways, offering them helpful information that will enable them to meet the emotional challenges of daily life. It can store data and information on line, and can also creat new applications. Providing them with quality information will enable them to navigate the emotional challenges of everyday life. This new trend gives rise to the phenomenon of on-line counseling [18].It can be used for mental guidance or as a means for support groups [19]. Miller and Gergen studied the use of an Internet bulletin board related to the topic of suicide and found that users in the group offered support and mutual aid [20][21].

The acceptance of contemporary EAPs has been facilitated by their association with the 'objective expertise' of the psy-professional, which offers a 'caring' and morally defensible basis for making disciplinary decisions; and by association with neutral and objective methods of recording and measurement. Electronic technology augments these associations through the apparent neutrality of the machine; by the 
apparent 'privacy' offered by the 'personal' computer, and by the possibility of disembodied participation in on-line para-therapeutic activities and discussions [22]. As Wallace notes, people are apparently more willing to confide their intimate problems to a computer, than to a real life counselor [23]. This promise - to render the potentially problematic inner lives of employees into an accessible and calculable form - makes the data compiled by EAPs all the more amenable to incorporation by behavioural risk management information systems.

Despite EAPs have already begun using on-line individual and group therapy [18] as a medium for counseling to its consumers, most practitioners are not familiar with web-based counseling groups. Galinsky surveyed 227 social work professionals and found that less than 50 percent were familiar with web-based group therapy [24]. But that tune is changeing, the range of services provided by EAPs has been larged by electronic technology. By the rapid growth of computers in the workplace and the increasing of the Internet, many providers automated EAP services. In the United State, more than one of two employed adults aged 25 use a computer. However, in recent years, the percentage using the internet at work has grown from 18 percent in 1998 to 42 percent in 2001 [25] The Internet has been described as an ideal vehicle for delivering 'cost-effective' mental health-care [26].Some contemporary EAPs have developed webbased programmes or 'life management systems' designed to be accessible and convenient for 'everyday use': The CAEP offers the cutting edge in EAPs uniquely accessible to all employees within the company 24 hours a day on their own office computers via the Internet [27].

\section{The case studies of web-based EAPs}

Here we introduce some specific cases:

Alcohol abuse. The Employee Stress and Alcohol Project (ESAP) developed an interactive computerbased alcohol abuse prevention [28]. By way of the Internet, early intervention program can be brought into effect for employees. ESAP is implementing this web site for a diverse 8567-employee work site. ESAPs' web site enables employees to ease their stress levels, coping styles and alcohol-related problems. It also provides resources for employees who are concerned about another individual's drinking as well as information about adolescent alcohol use. Behavioral health research can provide effective approaches to alcohol abuse prevention, early intervention, and treatment in the workplace managed care.
There was also a web-based training for EAPs counselors on screening and brief intervention(SBI) for alcohol abuse. The training had four learning objectives:(1)increase counselors' awareness and sense of importance of at-risk drinking as a health behavior,(2)increase their sense of preparedness to deliver the brief intervention,(3)increase their sense of self-efficacy in helping clients with health behaviors, including at-risk drinking, and(4)increase their perceptions of the efficacy of counselors in general in dealing with health behaviors [29]. The results showed increases in counselors' recognition of health behaviors sense of self-protection, and sense of selfefficacy in dealing with health behaviors. These results suggest that Web-based training is an effective mode for teaching EAPs counselors.

Medical service. This research is the comparative analysis the situation of teaching hospital about the implementation of EAPs. Researchers chose two hospitals located in Taiwan south. Through the interviews of the high-level managers and executives, the scene for realizing modern hospitals' EAPs can be constructed. The research found the following advantages when merging network into EAPs: (1) the property of network anonymous can protect the privacy (2) internal resource can be used more efficiently (3) information service can be supplied more personally (4) the employees' performance can be tracked more effectively which can build more sophisticated supervisor system. The above results can offer reference to the medical institutes that pursuing webEAPs [30].

In medical science, there are several study ways using the Internet: (1)Synchronous long-distance teaching: With the video meeting system, offer far the network of the distance study the way; (2)Course of the webpage : Utilize webpages to offer and have a class to the teaching material of teaching materials, can combine video-information to select at the same time ; (3)Fictitious classroom: Offer the chatroom moving ahead simultaneously, or discuss the non-synchronous interdynamic zone of discussion to different themes; (4)Computer assists and studies the case: Offer the simulation clinical true case study way. It can effectively treat patients, but also can give consideration to clinical teaching and can break the restrictions of the time and space in study.

American Airlines. The study of the American Airlines(AA)' employee communications response in 2001, explores how AA used different technologies, including corporate email, employee intranet, prerecorded hotline messages, Internet kiosks, the proprietary SABRE airline reservations system, and fax-on-demand technologies to communicate with employees. This study extends crisis communication 
scholarship within internal employee communication [31][32] and the apply of emerging communication technologies during a crisis [33][34][35].

The use of communication technologies has not been fully recognized and incorporated into employee crisis communication research. The results from this case study of the AA's employee communications response have at least two implications for crisis communicators. First, after a crisis, the mediated channels can effectively support communication. These channels include email, employee portals/intranets, executive hotlines, fax-on-demand technologies, and proprietary systems like SABRE [35]. Secondly, the use of the Internet employee communication vehicles make the airline's CEO to focus his efforts on communicating to external publics [36][37].

APSHelpLink ${ }^{\text {TM}}$. APS Healthcare is a private, forprofit, managed behavioural healthcare organization. It offers 'managed behavioural health, EAPs and management services to employees in the US and Puerto Rico'. Meanwhile, APS Healthcare also invests in the provision of managed behavioural health. It provides 'ongoing education and prevention, early intervention, and short-term problem resolution', and considers EAP as an effective and affordable way to encourage healthy lifestyles and detect problems which could impact the productivity. These services in turn will reduce the risk of unnecessary health care costs [38].

APSHelpLink $^{\mathrm{TM}}$ is the external platform of APS Healthcare. As a 'high-value low-cost benefit', it helps both employers and everyday consumers. Employers are promised 'reduced absenteeism, employee retention, and increased visibility', while employees are promised 'ease of access, convenience, consumer information, and interactive self-help tools and resources'. This website has been 'designed and written to be accessible to everyday people living in the real world'. Thus it is 'dynamic and brief' and offers a 'high degree of interactivity' with the user. The aims of APSHelpLink ${ }^{\mathrm{TM}}$ are 'compelling', 'convenient' and 'fun'. It could be co-branded, as an extension of a company's existing employee services [27]. Company intranet can be readily incorporated with APSHelpLink ${ }^{\mathrm{TM}}$.

In addition, APSHelpLink ${ }^{\mathrm{TM}}$ is not only designed to help employees to identify and alleviate early signs of personal or psychological problems. The organisation, content, and structure of this website are based on the latest research, including how the brain works and the most effective methods and theories of how people change. Specifically, Prochaska and DeClemente's ' readiness to change' model informs the site's design [39]. This is a cognitive-behavioural model often employed in the public health and mental health promotion fields in order to persuade people to recognize and change their unhealth habits. According to this model, APSHelpLink ${ }^{\mathrm{TM}}$ offers an unambiguous benefit to all employees through the offer of structured guidance through self-directed life change [27].

The APSHelpLink ${ }^{\mathrm{TM}}$ site goes beyond either the provision of psycho-educational information, or professional advice. Rather, APSHelpLink ${ }^{\mathrm{TM}}$ goes beyond assisting people change the way they think about their lives. These concrete and measurable changes are available both by the empowered employee, and by concerned employers. APS offers employers access to the results of a 'utilization analysis' for their employees: number and percentage of on-line visits by topic, content and function; duration of visits; number of visits spent in life problem areas; number and percentage of visits to online features (Search, Phone A Counselor, Chats, Find A Clinician, etc.); user visit frequency by area. APSHelpLink ${ }^{\mathrm{TM}}$ advises that they can track, by problem type, an individual's success on following through on the goals that they set for themselves [27]. This promise makes the data compiled by EAPs all the more amenable to incorporation by behavioural risk management information systems.

\section{Future direction}

In China, the researches and application of the EAPs are at the initial stage yet, so inevitably there are many problems. With the rapid economic development of China, the competition is more and more fierce, and the psychological problems become increasingly serious. Take the EAPs into organization is at the drop of a hat. Therefore, there is an urgent task that enhances the local research and application of EAPs, enhances the building of high-quality employee assistant counseling team.

On account of Chinese Feature, Kan thought that we should take the health organization as the starting point and entry point for EAP projects, and treat EAPs from organization, community level rather than the individual level. On this basis, he proposed EAPs in our country should plan to research and practice from the following six aspects: the coordination of labor relations and psychological behavior; response and management of disaster; stress management and health work; organizational change in the employee counseling; employee career development guidance; the construction of innovative organizational culture [40].

Athough the EAPs is for benefit of employees, with the development of EAPs, the contents of EAPs and 
human resources management has been more and more overlap. From the constitution of program to implementation details of each step, to the feedback of information results, the whole process of EAPs all permeate "treasuring people", "respect people", "taking care of people", " human centered" and other human management concepts.

As the research and application of EAPs relates to a wide range area, the quality of the consultants is also demanded higher. But currently the consultants of EAPs are mainly psychologists, the structure is single. There are a considerable number of consultants does not receive the training of management, human resources management and other organizational structure and transform, or have no experiences. The EAPs agencies and consultants lack of certification evaluation and management, and the approaches are some mental health services. These problems will definitely affect the further development of EAPs' research and application. Therefore, Web-based EAPs can attract a large number of experts and scholars, they can give advices and suggestions at any time on the Internet. EAPs refered to common employees for appropriate diagnosis, treatments and helping agencies, and provide case monitoring and tracking services. In this process, the Internet plays an important role which can effectively track the progress of treatment at any time, and it makes the confidentiality of employees which make employees pour out their feelings more easily and promptly to ease their stress.

Contemporary EAPs are concerned to detect and avert potentially costly personal problems, via selfdirected and motivational programmes such as those contained in structured web-based applications. The 'motivational logic' of web EAPs marks the transition of the programmes from an earlier focus on the scientific management of the productive subject, and the moral management of the 'sober, saving, steady, industrious' employee, to the neoliberal governance of the 'life and life conduct of the ethically free subject' [41], who strives for self fulfilment, personal growth and autonomous work-life management [27]. Thus the exercise of authority has become a therapeutic matter as perhaps the most efficient way of acting upon the actions of others is to change the ways in which they will govern themselves, or by 'Helping people to help themselves'. According to Lyon, care and control define the 'two faces' of surveillance - the suasive logic by which postindustrial surveillance systems operate [42]. EAPs offer a form of preventative surveillance organized overtly around the logic of 'concern' rather than 'control'. This mode of preventative surveillance, unlike classic disciplinary forms, does not rely on the coercive co-presence of the 'watcher and the watched' [43] and indeed, web-based
EAPs have been seamlessly incorporated as a 'convenient and compelling' benefit of relevance to all employees and their families, and as an ever-accessible tool for managing the everyday details of one's life and work [27]. For, as Lyon [42] reminds us, 'our daily experiences of surveillance occur in mundane moments rather than in special searches, "surveillance is 'designed in' to the flows of everyday existence" [44]'. Therefore, taking the web approach to carry out EAPs can be the future of the development of EAPs.

\section{Conclusion}

All in all, when merging web into the EAPs, we found the following advantages: (1) The characteristic of the Internet which is anonymous can protect the privacy of consultants. They can chat with impunity, pour out feelings, to reduce the burden of work and life to ease the pressure. (2) Internal resources can be used more efficient, we can get the latest knowledge and information. The convenience, information of study are instant and make use of web to carry on colony's cooperation to study.(3) Making use of web to do knowledge to search, or sharing one's own knowledge with other learners, have relevant effects to the study of the colony or the individual. (4) Information service can be supplied more personally (5) by way of the Internet, the employees' performance can be controled more effectively, and it can build a more effective and sophisticated systerm. If we can make the best use of the web-based EAPs, it must bring positive influence for organizing the companies and promoting the development of enterprises.

\section{References}

[1] A. K. Kirk and D. F. Brown, "Employee assistance programs: a review of the management of stress and wellbeing through workplace counselling and consulting", Australian Psychologist, 2003, vol. 38 (2), pp. 138-143.

[2] S. D. Brandes, Amencan Welfare Capitalism, Ill: University of Chicago Press, Chicago, 1970.

[3] I. Carter, "Social work in industry: a history and a viewpoint", Soc Thought, 1977, vol.3, pp.7-31.

[4] D. Nelson and S.Campbell, "Taylorism versus welfare work in American industry: W.J. Gault and the Bancrofts". Business Hist Rev, 1990, vol. 46, pp. 1-18.

[5] W. J. Dickson and F.J. Roethlisberger, Counseling in an Organization: A Sequel to the Hawthome Researches, Cambridge, Mass: Harvard University Press, 1966.

[6] E. Mayo, "Irrationality and reverie", JPersonnelRes, 1923, vol. 1, pp. 477-483.

[7] C. Perrow, Complex Organizations: A Critical Essay, Glenview, Ill: Scott, Foresman, 1972.

[8] F. J. Roethlisberger and W. J. Dickson, Management and the Worker, Cambridge, Mass: Harvard University Press, 
1939.

[9] C. A. Ferguson and J. E. Fersing, The Legacy of Neglect. Ft Worth, Tex: Industrial Mental Health Associates, 1965.

[10] R. D. Myrick, Develop guidance \& counseling:: practical approach (4rd), MinnEAPsolis, MV: Educational Media Coportion, 2003.

[11] P. M. Raskin, IVocational counseling: A guide for the practitioner, New York: Teacher College Press, 2001.

[12] R. J. Fang, T. S. Tsai, T. H. Huang, S. M. Su and K. F. Hall, "A Study of Web-Based Employee Assistance Programs in the Teaching Hospital", Proceedings of the 6th WSEAS International Conference on Applied Computer Science, Hangzhou, China, April 15-17, 2007.

[13] National Survey of Worksite Health Promotion Activities: A Summary. Washington, DC: US Dept of Health and Human Services, Office of Disease Prevention and Health Promotion, 1987.

[14] Survey of Employer Anti-Drug Problems, Washington, DC: Bureau of Labor Statistics, January 1989.

[15] H. Hayghe, "Anti-drug programs in the workplace: are they here to stay?", Monthly Labor Rev, 1991, vol. 4, pp. 2628.

[16] T. Blum, J. Martin and P. Roman, "A research note on EAP prevalence, components and utilization", JEmployment Assistance Res, 1992, vol. 1(1), pp. 209-229.

[17] T. D. Hartwell, P. Steele, M. T. French, F. J. Potter, N. F. Rodman and G. A. Zarkin, "Aiding troubled employees: the prevalence, cost, and characteristics of employee assistance programs in the United States", American Journal of Public Health, Vol. 86, Issue 6, pp. 804-808.

[18] K. Onstad and B. Banks, "Oedipus clicks", Canadian Business, vol. 70(11), pp. 14.

[19] F. D. Cutter, Virtual psychotherapy? Psychnews International,Available:http://www.cmhc.com/pni/pnil3b.ht $\mathrm{m}$.

[20] J. K. Miller and K. J. Gergen, "Life on the line: The therapeutic potentials of computer-mediated conversation", Journal of Marital and Family Therapy, vol. 24(2), pp. 189202.

[21] D. Masi and M. Freedman, "The Use of Telephone and on Line Technology in Assessment, Counseling, and Therapy”, Employee Assistance Quarterly, vol. 16(3), pp. 49-63.

[22] S. Hansen, "From 'common observation' to behavioural risk management: workplace surveillance and employee assistance 1914-2003", International Sociology, 2004, vol. 19(2), pp. 151-171.

[23] P. Wallace, The Psychology of the Internet, Cambridge University Press, Cambridge, 1999.

[24] M. J. Galinsky, J. H. Schopler and M. D. Abell, "Connecting group members through telephone and computer groups", Health and Social Work, 1997, vol. 22(3), pp. 181-188.

[25] US Department of Commerce, A Nation Online: How Americans Are Expanding Their Use of the Internet. Washington, DC: US Department of Commerce, 2002

[26] R. Bashshur, 'Telemedicine and the Health Care System', in R. Bashshur,J. Sanders and G. Shannon (eds) Telemedicine: Theory and Practice, Springfield, IL: Charles C. Thomas. 1997.
[27] T. F. Kristine, E. W. Stanley, M. M. Lisa, and W. L. Cynthia, "Project: The Development of a Computer-Based Alcohol Abuse Prevention Program for Employees", The Journal of Behavioral Health Services \& Research, May. 2000, vol. 27(2).

[28] B.Jeremy, M. Michael, B.L. Martiny, L. Richard, M. Bonnie, G. David and H.B. John, "Evaluating Web-Based Training for Employee Assistance Program Counselors on the Use of Screening and Brief Intervention for At-Risk Alcohol Use", Journal of Workplace Behavioral Health, 2009, vol.24(3), pp.307-319.

[29] T. Coombs, "The Internet as potential equalizer: New leverage for confronting social responsibility". Public Relations Review, 1998, vol. 24, pp. 289-304.

[30] R. R. Ulmer, and T. L. Sellnow, "Crisis management and the discourse of renewal: Understanding the potential for positive outcomes of crisis". Public Relations Review, 2002, vol.28, pp.361-365.

[31] P. Argenti, "Crisis communication: Lessons from 9/11", Harvard Business Review, 2002, vol. 80, pp. 103-109.

[32] M. E. Murgolo-Poore, L. F. Pitt, and M. T. "Ewing, Intranet effectiveness: A public relations paper-and-pencil checklist". Public Relations Review, 2002, vol 28, pp. 113 123.

[33] J. R. Downing, “American Airlines' use of mediated employee channels after the 9/11 attacks", Public Relations Review, 2004, vol. 30, pp. 37-48.

[34] H. Burson, "Damage control in a crisis", Management Review, 1995, vol. 84, pp. 42-45.

[35] W. Small, "Exxon Valdez: How to spend billions and still get a black eye", Public Relations Review, 1991, vol. 17, pp. 9-26.

[36] APS Healthcare, Available: www.apshealthcare.com (accessed 4 April 2003), 2003.

[37] R. Bunton, S. Baldwin, D. Flynn and S. Whitelaw, "The Stages of Change Model in Health Promotion: Science and Ideology", Critical Public Health, 2000, vol.10, pp. 55-70.

[38] K. Shi, X.L. Wang, M. Xu, "The development and thinking of EAP in China". New Capital, 2006, vol. 3, pp. 16-17.

[39] P. Miller and N. Rose, 'Governing Economic Life', in M. Gane and T.Johnson (eds) Foucault's New Domains, London: Routledge, 1993.

[40] D. Lyon, Surveillance Society: Monitoring Everyday Life, Milton Keynes: Open University Press, 2001.

[41] R. Castel, 'From Dangerousness to Risk', in G. Burchell, C. Gordon and P. Miller (eds) The Foucault Effect, Hemel Hempstead: Harvester Wheatsheaf, 1991.

[42] N. Rose, Governing the Soul: The Shaping of the Private Self (2nd), London: Free Association Books, 1999. 